where sex workers and clients meet. But the strategy does not explicitly tackle health and human rights and will not, therefore, tackle genuine areas of vulnerability and exploitation. Currently, children are sexually abused, people are trafficked and enslaved, and vulnerable individuals, including those with drug dependency or mental health conditions, are coerced and controlled, often by organised criminal gangs. Neither adult sex workers nor clients dare to report these abuses for fear of exposing their own involvement in sex work.

The proposed strategy rejects calls to license premises which comply with ordinary requirements of workplace legislation on health, safety, and labour. A licensing system could ensure that children were not employed, employees were not in possession of drugs, and foreign nationals had work permits.

Instead the strategy focuses on disrupting street sex markets. Kerb crawling will be policed in established red light areas despite strong evidence that this will simply displace sex work to other locations and increase the prevalence of acquisitive crime. ${ }^{3}$ This will also reduce sex workers' negotiating powers, make it harder for them to find clients, increase their time on the streets, and force them to solicit more directlyincreasing the risk of causing offence or distress to people not looking for paid sex. These conditions are directly linked to increased violence, pressure to abandon safer sex practices, and increased public disorder, including vigilante attacks. ${ }^{4}$

Sex workers are now uncertain about their legal status and are unsure whether the new Home Office strategy has become law. Outreach services and health researchers have noted increased fears among sex workers regarding the safety and confidentiality of such services.

Specialist healthcare services in red light areas face an uncertain future. Outreach work, provision of condoms, needle exchange schemes, and primary care for a population rarely registered with a general practitioner could be compromised if the strategy is enforced and sex workers become reluctant to seek help. Without access to specialist fast track services for sexual health, sex workers may face delays in receiving treatment for sexually transmitted infections, which could have profound consequences both for sex workers and the wider population.
The recent increase in sexually transmitted infections in the general population in the United Kingdom contrasts with a reduced prevalence in female sex workers. ${ }^{5}$ And the prevalence of HIV infection in sex workers, mainly associated with injecting drug use, remains lowbetween $0 \%$ and $3.5 \%{ }^{5}$ Sex workers have a responsible approach to managing the risk of sexually transmitted infections, with a high prevalence of condom use for commercial vaginal sex $(98 \%)$. The Home Office strategy shows inadequate understanding of risk, and the proposed changes could increase negative health outcomes, while limiting patients' access.

Multiagency work by healthcare professionals, police, social services, and sex workers will be disrupted if red light areas are phased out as the strategists intend. This will increase the risks to sex workers, 87 of whom have been murdered in the United Kingdom since $1990 .{ }^{6}$ Collaborative working gives sex workers the support to report violent clients and other predators who aim to coerce and control them. The lack of detail in the strategy about implementing the new approaches, especially regarding indoor sex work, leaves most of the sex workers we have spoken to feeling uneasy that they will have to wait and see how the strategy affects their access to health care and their contact with the criminal justice system.

Petra Boynton non-clinical lecturer in healthcare research (p.boynton@pcps.ucl.ac.uk)

University College London

Linda Cusick reader in substance use

(linda.cusick@paisley.ac.uk)

Institute for Applied Social and Health Research, University of Paisley

Competing interests: $\mathrm{LC}$ is the academic representative on the board of the UK Network of Sex Work Projects.

1 Home Office. Paying the price. London: Home Office, 2004. www.homeoffice.gov.uk/documents/paying_the_price.pdf

2 Home Office. A coordinated prostitution strategy and a summary of responses to paying the price. London: Home Office, 2005. www.homeoffice.gov.uk documents/cons-paying-the-price

Hubbard P. Community action and the displacement of street prostitution: evidence from British cities. Geoforum 1998;29:269-86.

4 Sanders T. The risks of street prostitution: punters, police and protesters. Urban Studies 2004;41:1703-17.

5 Day S, Ward H. Sex work, mobility and health in Europe. London: Kegan Day S, Ward
Paul, 2004.

Kinnell H. Violence and sex work in Britain. In: Day S, Ward H, eds. Sex work, mobility and health in Europe. London: Kegan Paul, 2004.

\title{
Oxygen treatment at home
}

\section{Will be better organised from 1 February in England and Wales}

I n England and Wales (but not in Scotland) prescriptions for oxygen concentrators have until now been written by the general practitioner, usually after assessment of patients and recommendation by respiratory specialists. Concentrators are then installed in patients' homes by companies that have regional NHS contracts. Patients using oxygen cylinders rather than concentrators receive supplies from local pharmacies after prescription by their general practitioners. From next week (1 February 2006) new arrangements will apply in England and Wales.
There will be three important improvements: all forms of home oxygen treatment will now be provided by a single supplier in each region of England and Wales after receipt of a home oxygen order form specifying the details of usage, such as flow rate and expected hours of use; ambulatory oxygen-including that supplied as liquid-will be generally available for the first time; and specialists based in hospitals will be able to order home oxygen directly. Indeed, respiratory medicine and paediatric teams will probably become the main prescribers of long 
term oxygen therapy and ambulatory oxygen treatment. General practitioners will still be able to prescribe oxygen, although this will probably be largely for use in emergencies and palliative care.

Long term oxygen treatment for patients with hypoxaemic chronic obstructive pulmonary disease was firmly established 25 years ago by two definitive trials that showed a survival benefit. ${ }^{1-3}$ Such treatment was greatly facilitated by the development of oxygen concentrators, which since 1985 have been available on the NHS. Around four fifths of patients using concentrators have chronic obstructive pulmonary disease, and although there is no evidence of survival benefit among patients with other conditions, such as pulmonary fibrosis ${ }^{4}$ and bronchiectasis, long term oxygen treatment by concentrator is often used if their arterial blood gas concentrations meet the criteria for this treatment.

Most home oxygen is, however, still prescribed in cylinders: approximately 63000 patients in England and Wales use cylinders and around 33000 use concentrators. Most patients use oxygen cylinders to deliver short bursts for symptom relief either before or after exercise or, in severe breathlessness, at rest. Lightweight portable systems suitable for use during exercise have not previously been generally available on NHS prescription, even though the potential benefit of ambulatory oxygen was shown 50 years ago. ${ }^{5}$ Refillable portable containers of liquid oxygen have advantages for some more active hypoxaemic patients but have been little used in the United Kingdom despite being widely available elsewhere in Europe. ${ }^{6}$

The indications and assessment criteria for long term oxygen therapy remain unchanged. ${ }^{7}$ But the new arrangements for providing oxygen therapy at home will require more detailed assessment of patients who are thought likely to benefit from such treatment. This is particularly important for patients who are active enough to be potentially suitable for ambulatory oxygen treatment: perhaps around half of the patients currently receiving long term oxygen therapy on the NHS. An uncertain number of patients not meeting the criteria for long term oxygen therapy but showing arterial oxygen desaturation on exercise may also benefit from ambulatory treatment. In general, ambulatory oxygen is indicated for well motivated patients who have oxygen desaturation on exercise and demonstrably better performance when breathing oxygen during exercise. Patients using short bursts of oxygen remain the most difficult to evaluate, however, and more studies on their needs are required. ${ }^{8}$ Whenever possible, both hypoxaemia and symptomatic benefit from oxygen should be demonstrable before oxygen is prescribed.

Assessing and monitoring patients more often will considerably increase the workload for the NHS. This will require a modest increase in staffing in respiratory medicine departments as well as improved liaison between secondary and community care. The British Thoracic Society's guidelines for assessment indicate that one additional respiratory nurse or other professional is needed per 100 patients receiving long term oxygen therapy. ${ }^{9}$ The Department of Health anticipates that the change should be "cost neutral," with the expenditure associated with ambulatory oxygen balanced by savings on inappropriate prescribing. It may prove impossible, however, to remove oxygen from patients whose treatment is established, even if this was prescribed inappropriately. Savings are more likely to come from more judicious assessment of those about to start treatment.

These more streamlined arrangements will be more convenient for patients and should allow many more to benefit from ambulatory oxygen. Given that there will be four suppliers nationally and given the variable performance of different oxygen equipment, it is essential that patients are assessed using the same equipment they will use at home. ${ }^{10}$ This applies not only to the oxygen source (concentrator, cylinder, or liquid) but also to interfaces (cannulas, masks, etc) and conserving devices (which limit wastage during expiration). Patients will need education and support especially during the period of transition. In particular, patients need to understand that shortness of breath does not necessarily imply shortage of oxygen.

Although considerably fewer children than adults receive home oxygen, they have special requirements for equipment such as flow meters and masks. Children need particularly frequent assessment as they grow, and many will probably need ambulatory oxygen because, even if they are not independently mobile, their parents and carers take them out.

Rationalisation of services for home oxygen treatment should allow patients earlier access to technological developments. Battery operated portable concentrators are already being marketed, and other prospects include concentrators which are able to refill cylinders or to liquefy oxygen for ambulatory use.

\section{G J Gibson professor of respiratory medicine}

(g.j.gibson@ncl.ac.uk)

University of Newcastle upon Tyne, Newcastle upon Tyne NE1 7RU

Competing interests: None declared.

1 Nocturnal Oxygen Therapy Trial Group. Continuous or nocturnal oxygen therapy in hypoxaemic chronic obstructive lung disease. Ann Intern Med 1980;93:391-8.

2 Medical Research Council Working Party. Long-term domiciliary oxygen therapy in chronic hypoxic cor pulmonale complicating chronic therapy in chronic hypoxic cor pulmonale
bronchitis and emphysema. Lancet 1981;1:681-6.

3 Cranston JM, Crockett AJ, Moss JR, Alpers J, Cranston J. Domiciliary oxygen for chronic obstructive pulmonary disease. Cochrane Database Syst Rev 2005;(4):CD001744.

4 Crockett AJ, Cranston JM, Antic N. Domiciliary oxygen for interstitial lung disease. Cochrane Database Syst Rev 2001;(3):CD002883.

5 Cotes JE, Gilson JC. Effect of oxygen on exercise ability in chronic respiratory insufficiency. Lancet 1956;1:872-6.

6 Garattini L, Cornago D, Tediosi F. A comparative analysis of domiciliary oxygen therapy in five European countries. Health Policy 2001; 8: oxygen

7 Royal College of Physicians. Domiciliary oxygen therapy services: guidelines and advice for prescribers. London, Royal College of Physicians, 1999.

8 Gallagher R, Roberts D. A systematic review of oxygen and airflow effect on relief of dyspnoea at rest in patients with advanced disease of any cause. J Pain Palliative Care Pharmacother 2004;18:3-15.

9 British Thoracic Society. Clinical component for the home oxygen service in England and Wales. 2004. www.brit-thoracic.org.uk/c2/uploads/ clinicaladultdec2004.pdf (accessed 20 Jan 2006).

10 Dheda K, Lim K, Ollivere B, Leftley J, Lampe FC, Salisbury A, et al. Assessments for oxygen therapy in COPD: are we under correcting arterial oxygen tensions? Eur Respir J 2004;24:954-7. 